\title{
Block Design Subtest (WISC-V)
}

National Cancer Institute

\section{Source}

National Cancer Institute. Block Design Subtest (WISC-V). NCI Thesaurus. Code C120356.

A subtest of the Wechsler Intelligence Scale for Children, Fifth Edition that measures spatial perception, visual abstract processing, and problem solving. 